\title{
PARAVERTEBRAL BLOCK AND THE ELECTROCARDIOGRAM IN ANGINA PECTORIS
}

\author{
BY \\ K. BRAUN \\ From the Medical Dept. (Div. B.), Rothschild Hadassah University Hospital, Jerusalem \\ Received October 21, 1945
}

Various surgical procedures in the region of the cervico-thoracic sympathetic system have been proposed for the treatment of angina pectoris. The paravertebral block of the upper thoracic sympathetic ganglia proved to be the most successful and the least dangerous. It was first introduced by Mandl (1925) who, using injections of noviocain, reported that he had achieved relief of pain for many weeks. Swetlow (1926) recommended the use of alcohol and thought by this modification to prolong the effect of the paravertebral block. The sensory nerves of the heart and coronary vessels pass through the middle and inferior cardiac nerves to the middle and inferior cervical ganglia. Since there are no white rami communicantes between the cervical sympathetic chain and the spinal cord these sensory fibres must descend to the upper thoracic ganglia, from where they finally reach the spinal ganglia (Ranson and Billingsley, 1918, and Stohr, 1928). Besides the cervical cardiac nerves, there exist thoracic cardiac nerves which also serve as sensory pathways (Brauecker, 1927; Jonescu, 1927; and White et al., 1933): these nerves pass directly through the posterior mediastinum to the upper four or five thoracic sympathetic ganglia. Thus, all the sensory pathways from the heart converge, uniting in the upper four or five thoracic ganglia. These anatomical facts explain the good results obtained by the paravertebral block of the upper thoracic ganglia (Marvin, 1935; Ochsner and DeBakey, 1937; and Levy and Moore, 1941).

Objections against any surgical intervention in the sympathetic nervous system as a method of treatment in angina pectoris have been raised by Danielopolu et al. (1931). They expressed the view that the sympathetics serve as vasodilators of the coronary vessels. Therefore, interruption of the sympathetic innervation may decrease the coronary flow and be even dangerous for a patient suffering from angina pectoris. Experimental studies on animals after ligation of the main coronary branches when the stellate ganglia or the thoracic ganglia have been removed do not, however, support this contention (Averbuck and Rachmilewitz, 1931; and White et al., 1933). On the contrary, it has been reported that under these conditions there is a decrease in the mortality rate of the animals after ligation of the main branches of the coronary arteries (Leriche et al., 1931).

The effect of the interruption of the sympathetic nerves on the coronary circulation in man is of special importance. Since in man coronary flow cannot be measured directly the use of the electrocardiograph affords the only method of revealing changes in the coronary circulation. The paper of Levy and Moore, who in 1941 reported their results in the treatment of cardiac pain by the paravertebral block contains also electrocardiographic observations. In 16 out of 45 patients cardiograms were taken and in 14 improvement was found. They assumed that the modification of the cardiogram indicated altering conditions in the coronary circulation.

The present investigation was carried out to study the effect of the paravertebral block on the electrocardiogram in cases of angina pectoris. A series of cardiograms was made in 12 patients treated by this method before and after the block. In 7 of them records were taken immediately before and twenty-four hours after the first injection to ascertain the 
immediate effect of the block. All patients were suffering from severe anginal pain and were under medical observation for some time before they were subjected to this treatment. The treatment consisted of 4-7 paravertebral injections, the interval between each of them being three to six days. For the first injection novocain only was used while the following injections were performed with novocain and alcohol.* Eleven patients showed cardiographic changes before the block. Three of these did not show any improvement of the cardiogram after the block. In the first the cardiogram showed signs of bundle branch block, in the second signs of a recent myocardial infarction of the posterior wall, and in the third four negative $T$ waves. In eight cases the cardiogram showed an improvement after the paravertebral block. The cardiographic changes in these cases were mainly concerned with the final deflection. Abnormalities of the $\mathrm{T}$ wave in at least two leads were present in all of them. The $T$ waves were negative, iso-electric, diphasic, or flattened. In some cases there was also a depression of the S-T segment. After the paravertebral block the $\mathrm{T}$ waves became positive or more elevated and the S-T depression disappeared. In four cases this positive effect was observed already twenty-four hours after the block, but the maximum improvement of the electrocardiogram was generally obtained at the end of the treatment.

Table I gives an account of the cardiographic changes that took place as the result of the paravertebral block. The degree of elevation of the $\mathrm{T}$ waves following this treatment was designated as + corresponding to an elevation of $0.5 \mathrm{~mm}$. $\pm 0.25 \mathrm{~mm}$.; as + + corresponding to an elevation of $1.0 \mathrm{~mm}$. $\pm 0.25 \mathrm{~mm}$; and as +++ corresponding to an elevation of $1.5 \mathrm{~mm}$. $\pm 0.25 \mathrm{~mm}$.

TABLE I

\begin{tabular}{|c|c|c|c|}
\hline \multirow{2}{*}{$\begin{array}{l}\text { Case } \\
\text { No. }\end{array}$} & \multirow{2}{*}{$\begin{array}{l}\text { Sex } \\
\text { and } \\
\text { Age }\end{array}$} & \multicolumn{2}{|c|}{ Electrocardiogram } \\
\hline & & Before treatment & At the end of treatment \\
\hline 1 & M. 46 & S-T I and IV depressed, T I, T IV inverted & S-T I and IV iso-electric, T I upright ++ , \\
\hline $\begin{array}{l}2 \\
3\end{array}$ & $\begin{array}{l}\text { F. } 48 \\
\text { M. } 51\end{array}$ & $\begin{array}{l}\text { T I, T IV iso-electric } \\
\text { T I iso-electric, T IV flat, P-R } 0 \cdot 25 \text {, QRS } 0 \cdot 13 \\
\text { sec. }\end{array}$ & $\begin{array}{l}\text { T I upright }+++ \\
\text { T I upright }++, \text { T IV upright }++\end{array}$ \\
\hline 4 & M. 57 & S-T I depressed, T I inverted, T II, T IV flat & S-T I iso-electric, T I upright,++ T II up- \\
\hline 5 & M. 51 & $\begin{array}{l}\text { S-T II depressed, T I inverted, T II, T III iso- } \\
\text { electric }\end{array}$ & $\begin{array}{l}\text { S-T II iso-electric, } \mathbf{T} \text { I upright }+, \text { T II up- } \\
\text { right }+\end{array}$ \\
\hline $\begin{array}{l}6 \\
7\end{array}$ & $\begin{array}{l}\text { M. 44 } \\
\text { M. 52 }\end{array}$ & $\begin{array}{l}\text { T I flat, T IV inverted } \\
\text { S-T I and II depressed, T I, T IV diphasic, } \\
\text { T II flat }\end{array}$ & $\begin{array}{l}\text { T I upright, }+, \mathrm{T} \text { IV iso-electric } \\
\text { S-T I and II iso-electric, T I upright }++, \text { T II }\end{array}$ \\
\hline 8 & M. 48 & $\begin{array}{l}\text { S-T I and II depressed, T I inverted, T II iso- } \\
\text { electric }\end{array}$ & $\begin{array}{l}\text { S-T I and II iso-electric, T I upright }+, \text { T II } \\
\text { upright }+\end{array}$ \\
\hline
\end{tabular}

A few typical case histories are given.

Case 3. J. A., aged 51, was admitted to the hospital on February 20, 1945. He was suffering for two years from attacks of pain in the præcordium with radiation to the left shoulder and arm. In the last seven months these attacks appeared very frequently, after the slightest effort and then even at rest, and therefore the patient was confined to bed for most of the time.

The clinical and X-ray examinations of the heart did not reveal any pathological findings apart from slight enlargement of the left ventricle. The blood pressure was 140/115. After ten days of observation, during which period the patient continued to suffer from anginal pain, the first paravertebral injection with novocain was done. Immediately after this procedure the pain subsided but appeared again a few days later. During one month five paravertebral injections with novocain and alcohol were performed. At the end of this period the pain disappeared.

A cardiogram done on the day before the paravertebral block showed left axis deviation, a prolonged P-R interval $(0.27$ sec.) and a slightly widened QRS in leads II and III. The T waves in the first lead were absent and in the fourth lead flat (Fig. 1A). Twenty-four hours after the first paravertebral injection the $T$ wave in the first lead became positive (Fig. 1B). At the end of the treatment

* A detailed description of the technique is given in F. Mandl, Paravertebral and Splanchnic Block, Grune and Stratton, New York, 1945. 
the $T$ waves in the first and fourth lead became normal while no change took place in the prolonged P-R interval (Fig. 1C).
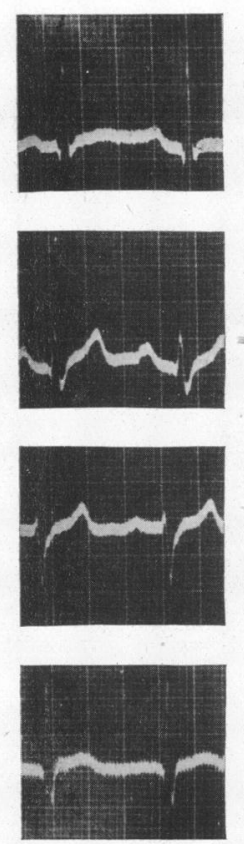

A
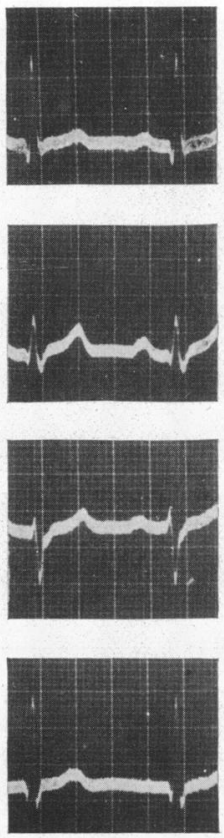

B
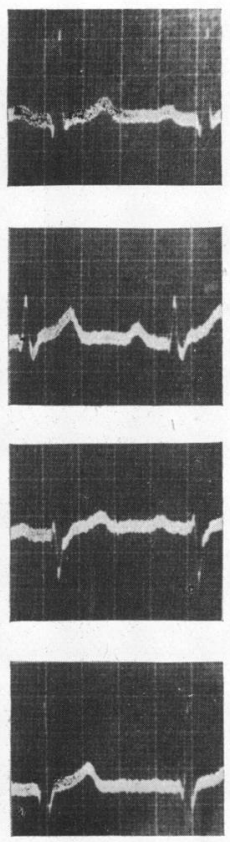

C

Fig. 1.-Case 3. (A) Iso-electric wave in lead I and flat T wave in lead IV. (B) Twenty-four hours after the paravertebral block; T I positive. (C) At the end of the treatment; elevation of T I and T IV. No change in the $\mathrm{P}-\mathrm{R}$ interval and in QRS after the treatment.

Case 4. P. R., aged 57, was admitted on January 23, 1944. Two and a half months before admission the patient had had an attack of severe pain in the præcordium. Since then he was suffering from continuous pressure in this region. Every effort or emotion increased the pain; even the shortest talk and the intake of food could precipitate an attack. His blood pressure was 140/100. The X-ray of the heart was normal. The patient was observed for one week during which period aminophyllin and sedatives were given. In spite of complete rest and the medical treatment he continued to suffer from frequent attacks of angina pectoris. On February 1, the first paravertebral injection of the upper two thoracic ganglia was done. This resulted in a marked relief of pain. During a period of three weeks seven injections with novocain and alcohol in the upper four thoracic ganglia were performed. At the end of this period the patient was practically painless.

Two cardiograms were made before the paravertebral block was performed and both of them showed the same pathological changes. The $T$ waves in the first lead were slightly negative and flat in the other leads (Fig. 2A). After the first paravertebral injection the $T$ waves in the first lead became low, upright and higher in the other leads (Fig. 2B). At the end of the treatment the cardiogram was practically normal (Fig. 2C).

Case 6. J. F., aged 44, was admitted on September 3, 1944. Six months before admission, after an effort the patient experienced an acute sharp pain in the chest which continued for a few hours. This attack was accompanied by severe dyspnœa. Since then the patient was suffering from repeated attacks of anginal pain which appeared after walking and the slightest effort. He was sent to our department in July, 1944, but because of an intercurrent febrile disease a paravertebral block could not be performed at this time. During the course of the disease numerous cardiograms were taken and there was a suspicion that the first attack of pain was caused by a myocardial infarction (anterior wall). In the last month the cardiographic tracings showed identical changes. On clinical and X-ray examinations a slight dilatation of the left heart was found. The blood pressure was 140/90. The heart sounds were normal. The laboratory examinations did not show any pathological findings. On September 5, a paravertebral block with novocain was done. The first and second thoracic segments were injected. Shortly after the injection anæsthesia and paresis developed in the left arm and hand. Because of this complication the paravertebral block was not continued. The pain in 
the chest disappeared completely after the injection, and while staying in the hospital for another month the patient did not feel any pain.

Immediately before the paravertebral block was performed a cardiogram was taken which showed left axis deviation, flat $T$ waves in lead $I$, and inverted $T$ waves in lead CF 4 (Fig. 3A). Twenty-four hours after the paravertebral block the cardiogram showed a change. The $T$ waves became higher,
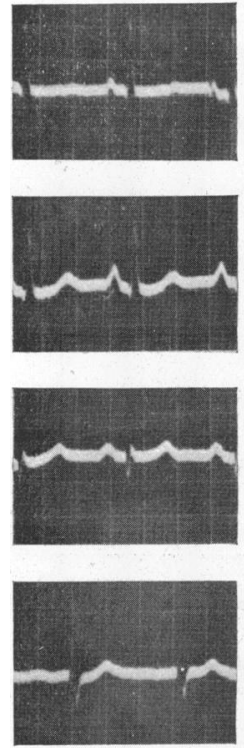

A
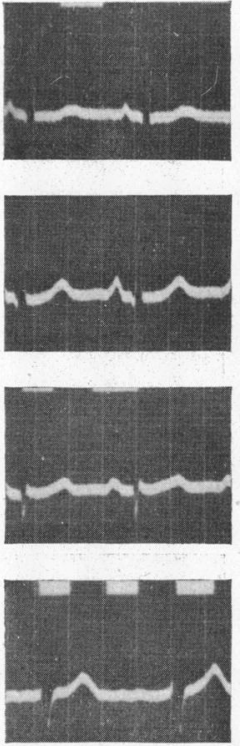

B
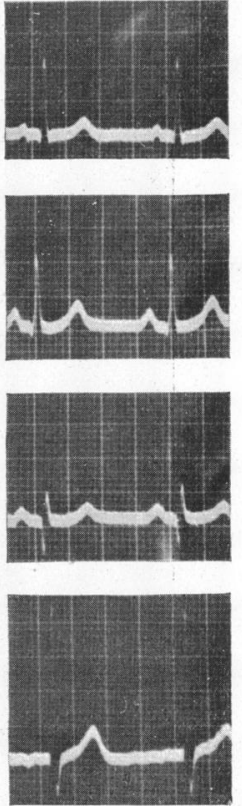

C

FIG. 2.-Case 4. (A) Negative T wave in lead I, flat T wave in lead II and IV, S-T II depressed. (B) Twentyfour hours after paravertebral block; T I positive, T II and T IV more elevated, S-T II iso-electric. (C) At the end of the treatment, the cardiogram shows further improvement and is practically normal.
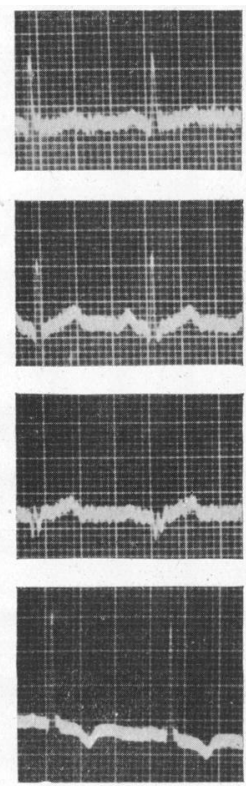

A
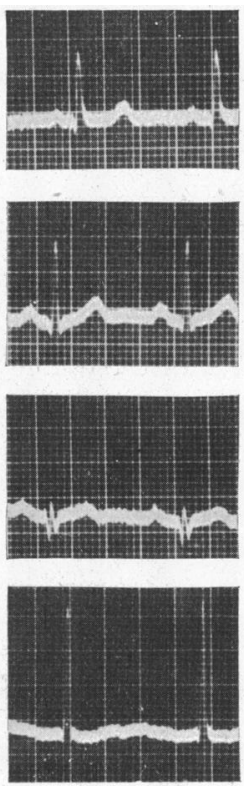

B
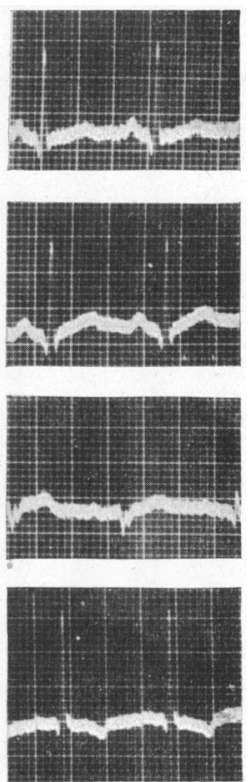

C

FIG. 3.-Case 6. (A) $\mathrm{T}$ wave in lead I flat and in CF 4 negative. (B) After novocain block; $\mathrm{T}$ I more elevated, T IV iso-electric. (C) Twenty-four hours later, the cardiogram shows the same changes as before treatment. The improvement was only temporary. 
upright in the first lead and iso-electric in the fourth lead (Fig. 3B). One day later the cardiogram showed the same pathological changes as before the paravertebral injection (Fig. 3C). The improvement was only temporary, and two days after the paravertebral injection the cardiogram showed the same changes as before the treatment.

\section{COMMENT}

The electrocardiographic changes found in our cases before treatment were concerned especially with the $T$ waves, alterations that are generally believed to be caused by anoxæmia of the myocardium due to a diminished coronary flow. The most frequent causes of a diminished coronary flow are arteriosclerosis and spasm of the coronary vessels. Anoxæmia is according to the present concept the chief cause of cardiac pain (Keefer and Resnik, 1918; Sutton and Lueth, 1930; Rothschild and Kissin, 1933; and Levy et al., 1938). While the relief of pain achieved by the paravertebral block can be explained by the interruption of the sensory pathways, the improvement of the cardiogram is most probably produced by an increased coronary blood flow and a greater oxygen supply to the heart muscle. The mechanism by which the improvement of the coronary circulation is achieved deserves special comment. It is agreed that the vasoconstriction of the peripheral vessels is mediated by the sympathetic nerves. But there is a discrepancy of opinion regarding the innervation of the coronary arteries. Leriche et al. (1931) assumed that the innervation of the coronary vessels follows the general law of vasomotor innervation and thought to have proved it by experiments in dogs: they ligated the descending branch of the left coronary artery at various levels and found that after ligation at higher levels the animals died from ventricular fibrillation, while after removal of both stellate ganglia the animals survived. Katz and Jochim (1939) found that cutting the sympathetic supply to the heart usually produced a coronary vasodilatation, sometimes, however, a vasoconstriction was noted; they concluded that the stellate ganglia send to the heart adrenergic coronary dilator and adrenergic coronary constrictor fibres. Evidence has also been accumulated indicating that the innervation of the coronary arteries is different from that of the systemic vessels. Anrep and Segall (1926) first showed that the vasoconstrictor fibres are carried chiefly in the vagus while the sympathetic nerves contain the vasodilator fibres. A series of investigations by improved methods confirmed these findings (Green et al., 1942; Essex et al., 1943). Recently also Gregg and Shipley (1944) showed that stimulation of the stellate ganglia and their cardiac branches causes an increase in the coronary blood flow.

The clinical experience with paravertebral block as a method of relieving pain in angina pectoris and our observations indicate that the blocking of the upper thoracic sympathetic ganglia may cause an improvement of the coronary circulation. The change of the cardiogram following this procedure furnishes objective evidence for the beneficial effect on the coronary blood flow. The improved circulation may be a direct sequel of the blocking of the sympathetic or the relief of pain may cause an abolition of reflex spasm in anatomically unaffected vessels and thus a dilatation of coronary vessels; this last possibility was assumed by Levy and Moore (1941). In our series of cases there was not always a parallelism between the improvement of the cardiogram and the persistence and severity of cardiac pain. In one of our patients (Case 6) a block with novocain of the upper two thoracic ganglia only was: performed: in this case there was an improvement of the cardiogram for twenty-four hours; but afterwards it showed the same changes as before treatment although the patient was relieved from his cardiac pain for several months. In other cases the cardiogram remained improved many months after the paravertebral block although the patients suffered again from attacks of angina pectoria.

In the three cases in which no improvement of the cardiogram after the treatment was observed, the cardiogram showed marked pathological changes (bundle branch block, myocardial infarction, and inverted $\mathrm{T}$ waves in four leads). It may be assumed that in these cases the changes in the cardiogram were caused by severe anatomical alterations in the coronary vessels and therefore no improvement could take place. 


\section{SUMMARY}

In twelve patients suffering from frequent attacks of angina pectoris the electrocardiogram was studied before and shortly after the paravertebral sympathetic block. Out of eleven cases with cardiographic abnormalities before the block, eight showed an improvement of the cardiogram. The $\mathrm{T}$ waves which before the block were flat, diphasic, iso-electric, or negative showed a tendency to return to normal. The improvement of the cardiogram did not always coincide with the relief of pain.

We take the opportunity of thanking Prof. F. Mandl and Dr. H. Melwidski, who performed the paravertebral injections.

\section{REFERENCES}

Anrep, G. V., and Segall, H. N. (1926). Heart, 13, 239.

Averbuck, S. H., and Rachmilewitz, M. (1931). Z. ges. exper. Med., 75, 552.

Brauecker, W. (1927). Beitr. klin. Tuberk., 66, I.

Danielopolu, D., and Proca, G. G. (1931). C. R. Soc. Biol, Paris, 107, 419.

Gregg, D. E., and Shipley, R. E. (1944). Amer. J. Physiol., 141, 382.

Green, H. D., Wegria R., and Boyer, N. H. (1942). J. Pharmacol., 76, 378.

Herrick, J. F., Baldes, E. J., Essex H. E., and Mann, F. C. (1943). Amer. J. Physiol., 138, 687. .

Jonesco, D., and Enachesco, M. (1927). C. R. Soc. Biol., Paris, 97, 977.

Katz, L. N.; and Jochim, K. (1939). Amer. J. Physiol., 126, 395.

Keefer, C. S., and Resnik, W. H. (1928). Arch. intern. Med., 41, 769.

Leriche, R., Hermann, L., and Fontane, R. (1931). C. R. Soc. Biol., Paris, 107, 545.

Levy, R. T., Barach, A. L., and Bruenn, H. G. (1938). Amer. Heart. J., 15, 187.

Levy, R. L., and Moore, R. L. (1941). J. Amer. med. Ass., 116, 2563.

Mandl, F. (1925). Wien. klin. Wchn., 38, 759.

Marvin, H. M. (1935). Bull. New York Acad. Med., 7, 453.

Ochsner, A., and DeBakey, M. (1937). Surgery, 2, 428.

Ranson, S. W., and Billingsley, P. R. (1928). J. Comp. Neurol., 29, 313.

Rothschild, M. A., and Kissin, M. (1933). Amer. Heart J., 8, 729.

Stohr, P. (1928). Mikroskopische Anatomie d. vegetativen Nervensystems, J. Springer, Berlin.

Sutton, D. C., and Lueth, H. C. (1930). Arch. intern. Med., 45, 827.

White, J. C., Atkins, J. A., and Garrey, W. E. (1933). Arch. Surg., 25, 765. 